\title{
ANÁLISE DOS FATORES QUE INFLUENCIARAM NA MODERNIZAÇÃO E NA EXPANSÃO DA AGROPECUÁRIA NO ESTADO DE GOIÁS
}

\section{Luiz Batista Alves}

Doutor pela Universidade Federal de Goiás - UFG/GO. Mestre pela Universidade Federal de Viçosa - UFV/MG. Professor Adjunto e Pesquisador da Universidade Estadual de Goiás - UEG. E-mail: lbalves@ueg.br. Professor Adjunto e Pesquisador da Faculdade de Ciências e Educação de Rubiataba - FACER e Ceres - FACERES. Email: luiz.batista.facer@gmail.com. Celular: (62) 9235-3288.

\section{Resumo:}

A proposta básica deste trabalho é tentar compreender como se dá a expansão de fronteiras no estado de Goiás verificando as relações entre o preço da terra e as variáveis de padrão tecnológico - terras irrigadas, número de tratores, investimentos, dentre outras. Realizou-se uma análise das correlações entre as variáveis preço da terra de pastagem e agrícola e as variáveis que compõem o nível de padrão tecnológico, chegando-se à conclusão de que a variação nos preços da terra não está associada à modificação da estrutura do nível de padrão tecnológico em função do baixo coeficiente de correlação encontrado. Isso pode ter ocorrido, talvez, por uma forte especulação de terras no território, pois a antiga região de fronteira foi se tornando saturada impedindo novas ocupações ou assentamentos.

Palavras-chaves: Frente de expansão, frente pioneira, renda diferencial, padrão tecnológico, coeficiente de correlação.

\section{ANALYSIS OF FACTORS INFLUENCING THE MODERNIZATION AND} EXPANSION OF AGRICULTURE IN THE STATE OF GOIÁS

Abstract:

The main purpose of this paper is to try to understand as how occurs the borders expansion in the state of Goiás showing the relationship between land price and the variables of technological standard, as irrigated lands, tractors number and investments among others. It has been done an analysis of correlations among variables as cattle and agricultural land price and composing variables of the level of technological standard, structure modification of technology standard, as function of low coefficient of found correlation. It could occurred, maybe, by a strong speculation of land prices in this area, as the ancient border region was been saturated obstructing new occupations and settlements.

Key Words: Expansion front, pioneer front, differential income, technological standard, correlation coefficient.

\section{Introdução}

Desde a década de 1930, com o início da transformação do Brasil de uma economia agrária em uma economia semi-industrializada, a expansão da fronteira agrícola se converteu na principal fonte de crescimento da produção agrícola brasileira. Isso foi possível graças a uma ampla disponibilidade de terras e ao dinamismo da demografia brasileira (MUELLER, 1985). A expansão da fronteira é associada, de forma geral, com a ampliação da moderna tecnologia agrícola com o desmatamento em regiões ainda não ocupadas por atividades produtivas (MIZIARA, 2006). 
O Cerrado, um dos hotspots brasileiros, tem enfrentado nas últimas décadas uma grande pressão proveniente da expansão da fronteira agrícola no país. A região CentroOeste é exemplo no Brasil de região de fronteira que se consolida como área de moderna produção agroindustrial após a transformação de sua base produtiva. Por um longo período foi caracterizada por um vazio demográfico e como região vocacionada para atividades agrícolas efetuadas de forma mais rudimentar - agricultura de subsistência, extrativismo e mineração.

Entretanto, a partir da década de 1930 consolidou-se como região de fronteira agrícola e pólo de absorção de excedentes populacionais. Assim, a partir do ano de 2000, a região passa a compor significativo percentual do Produto Interno Bruto (PIB) nacional, com destaque na produção de soja, algodão e carnes, entre outros, produzidos em sistema tecnologicamente mais avançado e intensivo em capital.

A Expansão de fronteira no Centro-Oeste tem diversos momentos, associados ao que a literatura denomina de "Frente de Expansão", "Frente Pioneira" e "Fronteira Agrícola".

Pelo estado da arte, usando o conceito de "Fronteira" como expansão da sociedade, os modelos teóricos usualmente adotados afirmam que esse processo ocorre em dois momentos distintos: Frente de Expansão e Frente Pioneira. Para compreensão de ambos os fenômenos, serão mais bem esmiuçados no próximo capítulo do presente trabalho, a maior parte dos autores utiliza duas variáveis, quais sejam: a Frente de Expansão se calca nas mudanças demográficas de regiões específicas, e a Frente Pioneira basicamente se ocupa das relações sociais.

Contudo, tal análise é insuficiente para explicar, por exemplo, "o fenômeno de reordenamento do espaço produtivo quando não ocorrem alterações significativas nas relações sociais de produção" (MIZIARA, 2006). Assim, tomando-se o modo de produção capitalista, tem-se como instrumento essencial para compreender a dinâmica do quadro agrícola no Centro-Oeste a teoria da renda fundiária, além dos já citados fenômenos Frente de Expansão e Frente Pioneira.

O presente trabalho se propõe a tentar compreender como se dá a expansão de fronteiras na região Centro-Oeste, verificando as relações entre o preço da terra e diversos fatores - terras irrigadas, número de tratores, investimentos. Na parte 2, no Modelo Teórico, se apresenta a revisão da literatura sobre os temas abordados. Na parte 3 - O caso de Goiás - se demonstram as correlações observadas entre as variáveis "preço da terra" (pastagem e agrícola) e variáveis que podem explicar a valorização ou não das terras, como "terras irrigadas", "quantidade de tratores", "investimentos", entre outras. A parte 4 - Resultados e Conclusões - apresenta considerações em relação aos resultados obtidos.

\section{Metodologia}

\subsection{Modelo Teórico}

Cabe, de início, apresentar uma breve explanação sobre o significado de "fronteira" com a finalidade de fundamentar teoricamente o trabalho. Para isso, são utilizadas as definições apresentadas por Martins (1975 e 1997), que utiliza as concepções de frente de expansão e frente pioneira para assinalar os movimentos de ocupação das áreas de fronteira, também distinguindo as fronteiras demográfica e econômica - a segunda sempre aquém da primeira, significando que o povoamento do território precede a sua real ocupação econômica. 
A "frente de expansão" é caracterizada por "uma ocupação de agentes da 'civilização', que não são ainda os agentes característicos da produção capitalista, do moderno, da inovação, do racional, do urbano, das instituições políticas e jurídicas etc." (MARTINS, 1997). A economia nesse caso é exercida por uma agricultura de excedentes, caracterizada em primeiro lugar pela busca da sobrevivência, sendo o excedente destinado a trocas mercantis. Nessa situação ocorre outro fenômeno, que é a terra não possuir valor de mercadoria: a frente é fortemente marcada pela utilização de terras devolutas do Estado mediante ocupação pura e simples, tendo como figuras centrais o ocupante e o posseiro. Como "frente de expansão" entende-se a primeira ocupação do espaço pela sociedade, efetuada por indivíduos ainda não inseridos diretamente no mercado. Nesse caso predominariam relações não-capitalistas, envolvendo posseiros, camponeses, etc., com a propriedade não capitalista da terra (posse). A frente de expansão seria dessa forma caracterizada "por uma economia de excedentes, absorção de excedentes demográficos e ausência da propriedade jurídica da terra" (FRANCO DA SILVA, 2006).

A chamada "frente pioneira" tem como traços distintivos a propriedade privada da terra e o empreendimento econômico. Nela estão embutidos os signos do capitalismo no campo, como empresas diversas, infra-estrutura, comércios, entre outros. Nessa modalidade a terra não é ocupada, e sim adquirida (MARTINS, 1975). De uma forma geral, Martins (1997) define fronteira como "um local de descoberta e desencontro dos diferentes entre si, como os índios e os civilizados, e os grandes proprietários de terras e os camponeses", também caracterizada pela ocorrência de conflitos no campo, freqüentemente ocorrendo ações violentas entre os posseiros, proprietários e o Estado. Enfim, a "Frente Pioneira" é marcada pelo avanço da relação capitalista de produção, principalmente pela apropriação capitalista da terra, processo esse intimamente associado ao uso da força, gerando inúmeros conflitos no campo.

No que concerne à "fronteira agrícola", essa tem como principal característica a mudança significativa no padrão tecnológico, associada à modernização conservadora da agricultura e fortemente relacionada com o nível de investimento. Assim, no processo de integração econômica promovido no Brasil a fronteira agrícola é uma área onde acontecem significativas transformações sociais e espaciais, com a introdução de novas relações de produção e de novos padrões tecnológicos, mercantis e financeiros. Uma característica desse processo é o conflito existente entre identidades culturais e territoriais já pré-estabelecidos na região e a inserção de novos valores.

Já no que concerne à renda da terra, os primeiros fundamentos gerais foram estabelecidos por David Ricardo e consolidados por Karl Marx.

Segundo Ricardo, i) as terras eram diferentes em sua fertilidade e todas as parcelas poderiam ser ordenadas da mais fértil para a menos fértil; e ii) a concorrência sempre igualava a taxa de lucro dos fazendeiros capitalistas que arrendassem terras dos proprietários. Esses eram os pressupostos básicos do que foi denominado "Lei da Renda Fundiária", segundo a qual os produtos das terras férteis são produzidos a custo menor, mas vendidos ao mesmo preço dos demais, proporcionando a seus proprietários uma renda fundiária igual à diferença de produção.

Marx elogia a teoria de Ricardo, dando como exemplo sua aplicação na colonização dos EUA: o povoamento acompanhou as terras mais férteis até um determinado momento, em que a distância da frente de povoamento em relação à costa torna viável a produção nas áreas vazias de terras menos férteis. Nesse ponto Marx introduz as variáveis "distância" e "fertilidade", fatores que definem a chamada Renda 
Diferencial, considerada a forma de renda mais importante para a explicação do tema fundiário. A Renda Diferencial é uma forma de lucro suplementar ${ }^{1}$, e pode ser obtida na agricultura de duas formas:

a) pela produtividade diferencial dos solos. O solo mais fértil do que o utilizado na margem de cultivo propicia ao seu proprietário esta forma de renda, ressaltando-se aqui a importância das condições naturais no processo de produção;

b) uma segunda manifestação da Renda Diferencial ocorre em função da distância da área de produção em relação ao mercado consumidor. Os terrenos mais próximos propiciam um barateamento nos custos de transporte.

Porém, Marx também criou um segundo conceito de Renda Diferencial, que é determinado pela quantidade de capital investido no solo através de equipamentos de irrigação e drenagem, entre outros, acarretando um maior volume de produção por área.

Em resumo, Marx define dois tipos de Renda Diferencial: a Renda Diferencial I, influenciada pelos fatores fertilidade e localização, e a Renda Diferencial II, que diz respeito ao capital investido nas terras, produzindo resultados diferentes em termos de produção (COSTA, s/d e FOLADORI, 2004).

Ou seja, a Renda Diferencial I é determinada pelas características naturais do solo explorado pelo capitalista. Os elementos em destaque são fertilidade e a localização, que permitem em tese menores gastos para produzir por área a mesma quantidade de produtos que no pior terreno, além de outros, como distribuição de impostos, desigualdade na distribuição de capitais, etc. (MIZIARA, 2006). E a Renda Diferencial II, determinada pela quantidade de capital investido no solo.

No que tange à expansão de fronteiras em Goiás, se verifica que suas diversas etapas seguiram o modelo básico acima apresentado, incorporando-se características e especificidades regionais.

Resumidamente, se podem enquadrar as etapas de expansão de fronteiras no Centro-Oeste da seguinte forma:

\section{Frente de Expansão}

No século XVIII, ao se descobrir ouro no oeste da região - zonas de Cuiabá e Corumbá - ali se radicou um significativo contingente populacional, com a incorporação de terras para uma agricultura de apoio às atividades de mineração. Com o declínio da atividade de mineração, ocorreu uma saída de parte da população, migrando e ocupando extensas áreas de terras ao norte e oeste da região, passando a desenvolver uma agricultura primitiva e de subsistência. A ocupação de terras no leste da região - ao sul de Goiás e leste de Mato Grosso do Sul teve uma origem semelhante, em que pese à "febre do ouro" que a originou tenha sido menos intensa. Em outros setores do sul do Centro-Oeste as dificuldades de acesso e o fato de que de não se descobrir minerais preciosos resultaram em que o povoamento e a ocupação de terras se iniciassem muito mais tarde. No sudoeste da região, por exemplo, o fenômeno só ocorreu no início do século XX (MUELER, 1980; MIZIARA, 2006).

\section{Frente Pioneira}

\footnotetext{
${ }^{1}$ Exemplo: o valor do produto é dado pelo tempo de trabalho socialmente necessário para sua obtenção. Assim, quem com o mesmo dispêndio de capital e trabalho conseguir uma produtividade maior, seja por aprimoramento técnico, seja por uma situação privilegiada no processo de produção, aufere sobrevalor acima da taxa média, um lucro suplementar.
} 
Essa teve início com a construção da Estrada de Ferro de Goiás, a partir de 1920. A estrada férrea possibilitou uma maior integração econômica da região com o restante do país, com um maior desenvolvimento das relações capitalistas de produção. Obviamente isso se refletiu na agricultura e na pecuária, que passaram a atuar com bases capitalistas.

A transferência da capital e a criação da Colônia Agrícola Nacional de Ceres marcam a marcha para o Oeste, a partir da década de 40, inserindo a região cada vez mais na economia de mercado (MIZIARA, 2006).

\section{Fronteira Agrícola}

Os dados de intensidade e técnica agrícolas mostram que, em 1950, todo o estado de Mato Grosso do Sul e o norte de Goiás tinham pouquíssimas atividades agropecuárias, mesmo as de baixo nível técnico. Em Goiás somente se verificavam vestígios de agricultura nos arredores de Goiânia e nos vales dos rios localizados ao sul do Estado, embora uma agricultura extensiva e de baixo nível tecnológico.

Entre 1950 e 1970 a expansão e o aumento da intensidade das atividades agrícolas se concentram quase que exclusivamente ao sul do estado, onde se encontram zonas nas quais se desenvolve uma agricultura tecnologicamente mais avançada.

Já no período entre 1970 e 1975 os índices de intensidade de cultivos correspondentes ao período mostram que nas zonas férteis localizadas ao sul de Mato Grosso do Sul se produziu uma extraordinária expansão agrícola: a maioria dos municípios apresenta taxas muito elevadas de crescimento de áreas cultivadas, com a incorporação de terras a uma agricultura com viés comercial e alto grau de mecanização.

Esse processo teve a participação de agricultores vindos de outras regiões brasileiras, com experiência em relação aos novos padrões tecnológicos adotados na agricultura. $\mathrm{O}$ fator atrativo é o do preço das terras, incluindo terras não utilizadas pela agricultura tradicional, como os chapadões.

Nesse ponto se encaixa a Renda Diferencial I: os produtores exploram um diferencial decorrente das condições naturais da terra.

\subsection{Operacionalização do Modelo}

\subsubsection{Definição e operacionalização das variáveis}

Dadas as premissas sobre frente de expansão, frente pioneira e fronteira agrícola para o estado de Goiás, pode-se observar o comportamento do processo de intensificação da agropecuária nos municípios em estudo por meio da análise de correlação entre os preços da terra para pastagem e agrícola, nível de investimento e mudanças no padrão tecnológico de acordo com a metodologia proposta. Os dados utilizados foram extraídos da Fundação Instituto Brasileiro de Geografia e Estatística dos Censos Agropecuários de 1970, 1975, 1980, 1985 e 1995/96 por meio do sítio http://www.ibge.gov.br (FIBGE, 2006).

As variáveis que explicarão o "padrão tecnológico" também, conceituadas pelo IBGE, são:

a) Total de cabeças de bovinos, em unidade;

b) Total de despesas com salários, arrendamento, adubos, corretivos, sementes, mudas, agrotóxicos, medicamento para animais, alimentação dos animais, combustíveis, lubrificantes, etc. deflacionado pelo deflator implícito do PIB nacional em reais de 2000; 
c) Investimentos realizados em cada ano deflacionado pelo deflator implícito do PIB nacional em reais de 2000;

d) Total de área irrigada em hectare;

e) Total de tratores existentes nos estabelecimentos em unidade.

\subsubsection{Coeficiente de Correlação (r)}

Segundo Hoffmann (1998), o coeficiente de correlação (r) mede o grau de associação entre Y e X, ou seja, mede o grau de covariabilidade entre duas variáveis em uma amostra. Para o caso em estudo, utilizaremos mais de duas variáveis, permitindo o cálculo e a análise do grau de covariabilidade entre Y e os demais X's.

O conceito de covariância entre duas variáveis é dado por

$\operatorname{cov}(X, Y)=\mathrm{E}\left(X-\mu_{X}\right)\left(Y-\mu_{Y}\right)$

e por definição o coeficiente de correlação entre X e Y é

$$
r=\frac{\operatorname{cov}(X, Y)}{\sigma_{X} \sigma_{Y}}
$$

onde $\sigma_{X}=\sqrt{\operatorname{var}(X)}$ e $\sigma_{Y}=\sqrt{\operatorname{var}(Y)}$.

Quando X e Y estão positivamente correlacionados ( $\mathrm{r}>0$ ), isto significa que o valor de $\mathrm{Y}$ tende a aumentar quando $\mathrm{X}$ cresce; e quando $\mathrm{X}$ e $\mathrm{Y}$ estão negativamente correlacionados $(\mathrm{r}<0)$, isto significa que o valor de $\mathrm{Y}$ tende a diminuir quando $\mathrm{X}$ cresce.

\section{Resultados e Discussões}

Segundo dados do IBGE, a região Centro-Oeste teve o melhor desempenho econômico em relação às outras regiões do país. Tem-se observado que as razões para este desempenho estão em sua diversificada base produtiva desde 1960 de forma acelerada e ocupações de grandes áreas em função do crescimento populacional.

A região Centro-Oeste teve taxas de crescimento econômico que resultaram em crescimento do produto per capita acima do observado para o Brasil. Apesar do setor agropecuário da região ter tido uma representatividade menor, em termos relativos, foi por meio da agropecuária que se deu a ocupação do espaço regional com uma maior integração com outras regiões, em nível comercial (MONTEIRO NETO e GOMES, 2000).

O estado de Goiás, no início dos anos 1960, considerado região de "fronteira", pois tinha uma densidade demográfica reduzida e exploração incipiente de suas potencialidades constituída, tinha apenas $44,0 \%$ de sua área explorada pela agropecuária e a expansão agrícola havia se dado de forma extensiva, valendo-se primordialmente dos fatores terra e trabalho com reduzida utilização de capital, segundo estimativas do IBGE.

Em decorrência de um modelo de desenvolvimento no início dos anos 1960, o estado de Goiás sofreu transformações importantes em sua estrutura sócio-produtiva. Em função disto tem-se observado que as indústrias a montante (de máquinas e insumos) e a jusante (indústrias transformadoras de matéria-prima agropecuária) tiveram suas técnicas de produção alteradas. 
Nas Tabelas 1 e 2 pode-se verificar o comportamento dos preços das terras em relação às variáveis que compõem o padrão tecnológico, definidos anteriormente, para os anos de 1970-1996.

Tabela 1 - Coeficiente de correlação entre Preço da Terra Pastagem e as variáveis de Padrão Tecnológico - Goiás - 1970-1996

\begin{tabular}{l|c|c|c|c|c}
\hline & \multicolumn{5}{c}{ Preço Terra Pastagem } \\
\hline \multicolumn{1}{c|}{$\begin{array}{c}\text { Variáveis de Padrão } \\
\text { Tecnológico }\end{array}$} & 1970 & 1975 & 1980 & 1985 & 1996 \\
\hline Total de Bovinos & 0,0082 & $-0,0335$ & $-0,0039$ & 0,0140 & $-0,0409$ \\
\hline Despesas Totais & 0,1745 & 0,1104 & 0,1141 & 0,1515 & 0,1523 \\
\hline Investimentos Realizados & 0,0996 & 0,0536 & 0,0423 & 0,0443 & 0,0006 \\
\hline Total de Área Irrigada & 0,1511 & 0,0048 & 0,0014 & 0,0612 & 0,0821 \\
\hline Total de Tratores Existentes & 0,2096 & 0,1530 & 0,1229 & 0,1215 & 0,0547 \\
\hline
\end{tabular}

Fonte: Cálculos da pesquisa.

Pode-se observar que para os anos de 1970-96, todas as variáveis consideradas de "padrão tecnológico" em estudo não tiveram relação com o preço das terras para pastagem, haja vista as mesmas apresentarem coeficientes de correlação bem próximos de zero. Observa-se que houve uma pequena representatividade de "despesas totais" no preço, porém, muito aquém do esperado. A variável "total de bovinos", além de apresentar baixa correlação no período, verifica-se até mesmo correlações negativas nos anos de 1975, 1980 e 1996, demonstrando que o preço da terra para pastagem não foi influenciado por esta variável.

Observa-se, também, que as variáveis "investimentos realizados", "total de área irrigada" e "total de tratores existentes" apresentaram baixa correlação durante o período observado, representando praticamente nenhuma influência desta variável no preço da terra para pastagem.

Tabela 2 - Coeficiente de correlação entre Preço da Terra Agrícola e as variáveis de Padrão Tecnológico - Goiás - 1970-1996

\begin{tabular}{l|c|c|c|c|c}
\hline \multicolumn{1}{c}{\begin{tabular}{c} 
Preço Terra Agrícola \\
\multicolumn{1}{c}{$\begin{array}{c}\text { Variáveis de Padrão } \\
\text { Tecnológico }\end{array}$}
\end{tabular}} & 1970 & 1975 & 1980 & 1985 & 1996 \\
\hline Total de Bovinos & $-0,0288$ & $-0,1160$ & $-0,0858$ & 0,0076 & $-0,0971$ \\
\hline Despesas Totais & 0,1454 & 0,0859 & 0,1093 & 0,2134 & 0,1816 \\
\hline Investimentos Realizados & 0,0538 & $-0,0105$ & $-0,0279$ & 0,0157 & $-0,0859$ \\
\hline Total de Área Irrigada & 0,2378 & 0,1582 & 0,0921 & 0,1844 & 0,0706 \\
\hline Total de Tratores Existentes & 0,1835 & 0,1392 & 0,0915 & 0,1307 & 0,0847 \\
\hline
\end{tabular}

Fonte: Cálculos da pesquisa.

Nos casos dos preços da terra agrícola (Tabela 2), os coeficientes de correlação ficaram, também, muito baixos e, em alguns casos, até negativos, significando pouquíssima influência nas variáveis de "padrão tecnológico". Porém, deve-se ressaltar 
que o "total de área irrigada" e "total de tratores existentes" na propriedade foram as que tiveram as maiores correlações durante o período analisado.

Isto demonstra mesmo em pequenas proporções, que dentre as variáveis de "padrão tecnológico" o "total de área irrigada" e "total de tratores existentes" teriam maior influência na variação no preço da terra para fins agrícola.

Na Tabela 3 pode-se verificar o comportamento das variáveis que compõem o padrão tecnológico, total de bovinos, despesas totais, total de área irrigada e o total de tratores existentes em relação aos investimentos realizados, para os anos de 1970-1996.

Essa análise será interessante neste trabalho justamente para verificar como o processo de investimento em tecnologia foi de fundamental importância para a modernização da agricultura em Goiás no período analisado.

Em função da necessidade de aumentar a demanda por máquinas e insumos por parte dos empresários e fazendeiros rurais, o setor industrial obteve uma "força" por meio do subsídio ao campo através do crédito rural.

Em Goiás, o comportamento do crédito rural apresentou tendência crescente, representando em torno de 7,0\% entre 1970 e 1995, em termos de valor em relação ao total concedido aos demais estados. Dessa forma, pode-se afirmar que o financiamento rural foi um importante instrumento de modernização da agricultura, pois possibilitou a incorporação de maquinários e insumos ao processo produtivo (ESTEVAM, 1998).

A intensidade de investimentos pode ser observada por meio do aumento acelerado do número de tratores na região. Esta variável é significativa porque a máquina viabiliza a utilização de implementos, tais como, arados, semeadeiras, pulverizadores, etc., além do aumento da área irrigada que possibilita a utilização com maior intensidade de equipamentos de irrigação e drenagem.

Nas atividades pecuárias, estes investimentos podem ocasionar aumentos no número de cabeças de gado e demais despesas inerentes ao processo de produção, tais como medicamentos e alimentação para os animais.

Tabela 3 - Coeficiente de correlação entre Investimentos Realizados e as variáveis de Padrão Tecnológico - 1970/1996

\begin{tabular}{l|c|c|c|c|c}
\hline & \multicolumn{5}{|c}{ Investimentos Realizados } \\
\hline \multicolumn{1}{c|}{$\begin{array}{c}\text { Variáveis Padrão } \\
\text { Tecnológico }\end{array}$} & $\mathbf{1 9 7 0}$ & $\mathbf{1 9 7 5}$ & $\mathbf{1 9 8 0}$ & $\mathbf{1 9 8 5}$ & $\mathbf{1 9 9 6}$ \\
\hline Total Bovinos & 0,8244 & 0,8284 & 0,9212 & 0,8034 & 0,8957 \\
\hline Total Despesas & 0,8344 & 0,8808 & 0,8792 & 0,7464 & 0,7106 \\
\hline Total da Ârea Irrigada & 0,3366 & 0,2310 & 0,0362 & 0,1253 & 0,3413 \\
\hline Tratores Totais Existentes & 0,7116 & 0,8163 & 0,8413 & 0,7897 & 0,7786 \\
\hline Valor dos Bens - Terras & 0,8926 & 0,8920 & 0,9214 & 0,8558 & 0,8586 \\
\hline
\end{tabular}

Fonte: Cálculo da pesquisa

Conforme a Tabela 3 pode-se observar que os coeficientes de correlação para todo o período analisado em relação a as variáveis de "padrão tecnológico" foram satisfatórios, pois se constata que os investimentos realizados no estado foram direcionados para intensificar o processo de tecnificação na agricultura e pecuária goiana.

Devido às antigas áreas de pastagens naturais, que foram melhoradas com o passar do tempo, a intensificação na criação de bovinos aumentou muito no estado de Goiás. 
Isto mostra que com os recursos financeiros aplicados no processo de produção da pecuária, houve um aumento na quantidade de cabeças de gado e consequentemente, um aumento nas despesas no trato dos mesmos, tais como alimentação e medicamentos.

Verifica-se, também, que boa parte dos investimentos realizados foram gastos ou utilizados nas despesas envolvendo o processo de produção agropecuário e na aquisição de tratores, que é um forte parâmetro para se verificar a tecnificação do setor agropecuário de Goiás. Pois, observa-se um coeficiente de correlação relativamente alto para a variável "tratores totais existentes", o que poderia se concluir que, do total de investimentos no setor agropecuário, boa parte destes recursos foram para adquirir tratores, melhorando a produtividade do setor.

Para o caso do total de área irrigada, verifica-se o baixo coeficiente de correlação, demonstrando pouca utilização desses recursos para a expansão da área irrigada. Porém, nas últimas décadas estas áreas expandiram-se originando grandes projetos de cultivo irrigado em algumas partes do estado.

Apesar de isto demonstrar certa obviedade nas análises, a insistência em apresentá-las é em função deste "padrão tecnológico" não influenciar diretamente no preço das terras em Goiás, conforme demonstrado nas Tabelas 1 e 2, observado pelos coeficientes de correlações.

\section{Conclusão}

Conclui-se que a reestruturação técnico-produtiva no estado caracterizou-se pelo emprego de máquinas e de insumos industriais que acelerou o processo de modernização agropecuária de Goiás. Além disso, as transformações na agricultura expandiram o espaço ocupado no campo dado os incentivos fiscais e financeiros disponíveis.

Houve melhorias nas antigas áreas de pastagens naturais a partir dos anos 1960, onde se intensificou a criação de bovinos. Isto repercutiu favoravelmente na multiplicação de frigoríficos e outras agroindústrias na região.

Estas transformações técnico-produtivas mexeram com a estrutura agrária no estado, onde o fluxo de empresários procedentes do Sul e Sudeste ocasionou uma maior concentração fundiária a partir de 1970, levando à valorização das terras.

Dessa forma, com base nas informações e dados coletados, o modelo inicialmente discutido não procede em afirmar que com o padrão tecnológico aplicado no período de análise tenha influência para explicar o preço das terras, haja vista os baixos valores dos coeficientes de correlação encontrados.

As terras foram valorizadas não em função da modernização da agropecuária em Goiás ou até em outros estados da região, mas da forte especulação de terras no território, pois a antiga região de fronteira foi se tornando saturada, impedindo novas ocupações ou assentamentos. Além disso, os programas governamentais e as inovações tecnológicas no campo rearticularam o espaço rural em Goiás intensificando o ritmo de concentração da propriedade fronteiriça.

No caso da Renda Diferencial, a conclusão que se chega é que os dados disponíveis atualmente do IBGE não nos permitem analisar esta incorporação de tecnologias para podermos efetuar as análises entre o que propõe Marx e Ricardo.

Sugere-se neste trabalho uma pesquisa mais aprofundada em dados que representem níveis de tecnologias no intuito de se obter a possibilidade de cálculo da Renda Diferencial e observar o que de fato pode estar por traz da valorização no preço das terras para o estado de Goiás. 


\section{Referências Bibliográficas}

COSTA, S. O modo de produção e a renda fundiária. Espaço Agrário, sem data.

ESTEVAM, Luís. Tempo da transformação. Goiânia: Ed. do Autor, 1998. 275 p.

FOLADORI, G. O metabolismo com a natureza. Crítica Marxista, 2004.

FRANCO DA SILVA, C. Fronteira agrícola capitalista e ordenamento territorial. In SANTOS, M., BECKER, B. Território: ensaios sobre ordenamento territorial. DP\&A, 2. ed., Rio de Janeiro, 2006.

FUNDAÇÃO INSTITUTO BRASILEIRO DE GEOGRAFIA E ESTATÍSITCA FIBGE. Censos Agropecuários de 1970/1975/1980/1985/1995-96. Rio de Janeiro. Acesso no sítio www.ibge.gov.br em 01 outubro de 2006.

HOFFMANN, Rodolfo. Estatística para economistas. São Paulo: Pioneira, 1998. 3ed. $430 \mathrm{p}$.

MARTINS, J. Fronteira: a degradação do outro nos confins do mundo. Hucitec, São Paulo, 1997.

MARTINS, J. Capitalismo e tradicionalismo. São Paulo: Pioneira, 1975.

MARX, K. O Capital: Crítica da Economia Política. São Paulo: Abril, 1984, V. III e VI.

MIZIARA, F. Expansão de fronteiras e ocupação do espaço no Cerrado: o caso de Goiás. In GUIMARÃES, L.; DANIEL DA SILVA, M.; ANACLETO, T. Natureza viva: Cerrado. UCG, Goiânia, 2006.

MONTEIRO NETO Aristides, e GOMES Gustavo Maia. Quatro décadas de crescimento econômico no Centro-Oeste brasileiro: Recursos públicos em ação.

Texto para discussão $\mathrm{n}^{\circ}$ 712. Brasília: IPEA, 2000.

MUELLER, C. La expansión de la frontera agrícola y el medio ambiente. La experiencia reciente del Brasil. In SUNKEL, O. Estilos de desarrollo y medio ambiente en la América Latina. Fondo de Cultura Económica, 1980. 